\section{Flour Mite, Acarus siro L., 1758, as a Species Complex}

Fon more than forty years Acarus siro L., 1758, a pest of harvestod cereals and ccreal products, has bcen considered a very variable species consisting of several forms. Zachvatkin ${ }^{2}$ concluded that these forms had no taxonomic significance since intermediate forms existed. Variation has boon attributed both to the adult stage and to the hypopus stage (deutonymph), which sometimes occurs in the life-cycle, generally in response to certain unfavourable conditions. Schulze ${ }^{2}$ described a motile migratory hypopus, capable of rapid movemont but becoming passive once it has attached itself to another arthropod, and an inert form incapable of movement or attachmont but resistant to desiccation. She ascribed both forms to A. siro, stating that both could be obtained from single pair matings.

A four-year study on hybridization, hypopus formation and the external morphology of populations of $A$. siro from stored products or outdoor habitats has shown thore is involvod a species complox made up of throe species. Each species is capable of producing only one kind of hypopus, either motile or inert. After an extensive rosearch into the litorature, it is considered that the complex contains $A$. siro L., $1758 ; A$. farris ${ }^{3}$ and a new specics.

When siro was crossed with the other two species only a small percentage of initial crosscs succeeded. In those, gamete mortality occurrod since each fertile pair yielded only a few offspring, $F^{\prime}$, hybrid sibling crosses did not produce offspring. Back-crosses to parent forms showed that $\hat{F}_{2}$ femalos were sterile, whoreas the majority of $\boldsymbol{k}_{1}$ males were fertile. Initial crosses between farris and the third species were moro successful; about 80 per cent of crosses produced some viable eggs. Both sexes of $F_{1}$ hybrids were fertile but only 25 per cent of $F_{2}$ and first back-cross eggs hatched. Fertility of $F_{2}$ sibling crosses was further reduced in that only 11 per cont of $F_{3}$ eggs hatched.

A. farris produces a motile hypopus and the new species an inert hypopus, quite froquently. Experimonts revealed that these two hypopi differ physiologically, particularly in respect to resistance to desiccation. Also, an examination of the genetics of the hybrid hypopi has shown that polygenic inheritance occurs. A few out of many populations of siro have produced a motile hypopus which is morphologically different from that of farris. However, hypopus production in siro is rare.

Following examination of material collected from all over Britain and from parts of Europo, Canada, United States, Chile, Kenya and Egypt, it is concluded that the form designated here as $A$. siro L. is a storod product mite. Since the type no longer exists, arrangements are being made to orect a neotype. Oudemans's syntypes of $A$. farris have been examined and I select as lectotype the single male specimen bearing the following data. Left label (black ink in Oudemans's handwriting and crossed through twice in pencil): Tyroglyphus farris Oudemans ot typo. Right label (black ink): in Kaas Arnhom 6. 2. 1902 Oudemans; below this is a small printed label stating: "Museum Leiden Verz. A.C. Oudemans collection Cat. No. 45". This species appears to occupy outdoor habitats.

A full account of this work is being propared for publication elsewhere in which the new species will be fully described and named. Meanwhile, in view of the economic importance of this species complex, a simplified key for the separation of the adults is appended. It is bascd on chrtotaxy of tarsus II of either sex, whon the tarsus is viewed laterally. The nomenclature of the seta follows Grandjean ${ }^{4}$.

(1) Spine $S$ at ventral apex of tarsus II large, about equal in length to tarsal claw; width of baso equal to length of spines' shortest edgc; tip of spine directed backwards. Solenidion omega $a_{1}$, on dorsal basal third of tarsus, recumbent with a distinct 'goose-neck' preceding terminal 'head'. A. siro L.

Spine $S$ fairly small, about half length of tarsal claw; width at base less than half the longth of spines' shortest edge; tip not directed backwards. Omega $a_{1}$ not recurnbent, not 'goose-necked'. 2.

(2) Omega, with sides almost parallel; an indistinct 'xock' expands into a well-formed cgg-shaped terminal 'head'. Widest part of 'head' exceeds widest part of stem. Acarus sp. n.

Omega $_{1}$ with sides diverging slightly from base, narrowing imperceptibly to an indistinct 'neck' then expanding slightly into terminal 'head'. Widest part of 'head' never wider than widest part of stem, $A$. ferris Ouds.

\section{A. Griffiths}

Agricultural Research Council,

Pest Infestation Laboratory, London Road, Slough, and

Royal Free Hospital Śchool of Medicine, University of London.

${ }^{3}$ Zachvatkin, A. A., Inst. Zowl, Acad, Sci. Moscow, N.S., No. zo (1941). ${ }^{2}$ Schulze, H., Centralbl. für Bakt. Abt. II, 60, 536 (1024).

3 Oudemans, A. C., Entomol. Ber., 2, No, 26, 20 (1905).

${ }^{4}$ Grandjean, F., Bull. So c. Zool., 64, 50 (1939).

\section{Juvenile Hormone Activity of Isomers of Farnesol}

Since the juvenile hormone of insects was first extracted from the abdomons of male cecropia moths ${ }^{1}$, its presence or the presence of juvenile hormone-like activity has been demonstrated in other insects ${ }^{2}$, in invertebrates ${ }^{8}$, in bacteria, yeast, and higher plants ${ }^{4}$, in certain organs of mammals ${ }^{5}$, and in the freces of the beetlo Tenebrio molitor ${ }^{6}$. Recently, the active constituents of the freces of $T$. molitor were isolated and identified as two related acyclic sesquiterpones, farnesol (I) and farnesal ${ }^{7}$, and the activity of one of them, farnesol, was oxamined in detail on the assassin bug, Rhodnius prolixus ${ }^{8}$. Although the juvonile hormone activity of farnesol was demonstrated, its unit activity was far loss than those of partially purified extracts of cecropia moths, and thorefore it is not likely that farnosol is the truo juvenile hormone of insects ${ }^{8, t}$. Nevertheless, interest is centred on those terpenes as possible precursors of the juvenilo hormone.<smiles>CC(C)=CCCC(C)=CCCC(C)=CCO</smiles>

(T)
We have also tested, and aro able to confirm, the juvenile hormone activity of farnesol and farnesal and another rolated terpene, nerolidol, on $T$. molitor pupæ; no activity was found in goraniol, citronellol, squalene, and mevalonic acid lactone. 